\title{
OVIDUCT SECRETION IN THE EWE AND THE EFFECT OF OVIDUCT FLUID ON OXYGEN UPTAKE BY RAM SPERMATOZOA IN VITRO
}

\author{
D. L. BLAGK, LEO V. GROWLEY, R. T. DUBY AND \\ G. H. SPILMAN \\ Laboratory for Reproductive Physiology, \\ Department of Veterinary and Animal Sciences, University of Massachusetts, \\ Amherst, Massachusetts, U.S.A.
}

(Received 20th March 1967, revised 17th May 1967)

In recent years, interest in the role played by oviduct fluids in reproduction has increased. With the development of a method for the continuous collection of oviduct fluid from the rabbit (Clewe \& Mastroianni, 1960) it became possible to measure the rate of oviduct secretion in the unanaesthetized animal. By slightly modifying their collection apparatus, oviduct fluid was collected from the ewe by Black, Duby \& Reisen (1963) and more recently by Perkins, Goode, Wilder \& Henson (1965), Restall \& Wales (1966) and Wales \& Restall (1966).

The oviduct provides a liquid medium for gametes during transport and fertilization. Whether this fluid does more than provide a protective environment is unknown. Spermatozoan respiration is stimulated by oviduct fluid from the cow (Olds \& VanDemark, 1957), rabbit (Hamner \& Williams, 1963) and ewe (Black, Crowley, Duby \& Spilman, 1966; Wales \& Restall, 1966). It has been suggested (Wales \& Restall, 1966) that the stimulatory effect of oviduct fluid on spermatozoan respiration is due to the presence of substrate.

Little attention has been given to the respiration stimulatory properties of oviduct fluid collected at various times during the oestrous cycle. Since the composition of oviduct fluid changes with the endocrine state of the animal, it seems likely that these changes would manifest themselves in the effect the fluid has on spermatozoan respiration.

These studies were undertaken to determine whether or not the ability of oviduct fluid to stimulate spermatozoan respiration changes during the oestrous cycle. In addition, the efficacy of the methods used in the collection of oviduct fluid was evaluated.

Twenty ewes demonstrating normal oestrous cycles were used in this study. Collection of oviduct fluid was carried out between September and January of 2 years. A collection device was attached to each animal as previously described (Black et al., 1963). The collection device was slightly modified by substituting a soft plastic vial and case for the collection chamber embedded in a solid plastic block. The plastic vial in which oviduct secretions accumulated was equipped with a removable cap through which passed the air vent tube 
and silicone rubber cannula from the oviduct. Each day the collection vial was replaced with a sterile one and the amount of fluid measured by drawing it into a $1-\mathrm{ml}$ tuberculin syringe and reading the volume. To help prevent infection, the vial cover and oviduct cannula were cleaned with $70 \%$ ethyl alcohol each time the vial was changed. Throughout the experiments, oestrus was detected by a vasectomized ram placed with the ewes once daily.

At the end of the experiment the animals were killed. Segments from the upper, middle and lower parts of both the cannulated and non-cannulated oviducts were fixed in Bouin's fluid, sectioned, stained with haematoxylin and eosin, and examined to determine if oviduct cannulation had an effect on the oviduct epithelium.

The composition of cell debris in oviduct fluid was studied in seven ewes. Secretions were centrifuged and smears made of the residues. All smears were air dried and stained with haematoxylin-eosin. Material in the smear was classified as follows: (1) erythrocytes, (2) polymorphonuclear leucocytes, (3) single epithelial cells with nuclei, (4) single epithelial cells without visible nuclei, (5) groups of epithelial cells with visible nuclei, (6) groups of epithelial cells without visible nuclei, and (7) free nuclei. An arbitrary grading system was used to denote the relative number of cells found in each of these groups.

Ram semen was obtained by electro-ejaculation. The ejaculate was immediately diluted with an equal volume of Ca-free Krebs-Ringer-phosphate (KRP) solution and centrifuged $(8 \mathrm{~min}$ at $200 \mathrm{~g}$ ). The supernatant was removed and discarded. Spermatozoa cells were washed two more times in the same manner and finally resuspended in KRP so that each millilitre contained approximately $1 \times 10^{8}$ cells. In all trials, direct counts of spermatozoa were made with a haemocytometer.

Oxygen uptake by spermatozoa was determined with a Warburg constant volume respirometer. One millilitre of the spermatozoa suspension was placed in each 7-ml single side-arm flask for incubation at $37^{\circ} \mathrm{C}$. Air was used as the gaseous phase and respiratory carbon dioxide was absorbed with $10 \%$ potassium hydroxide in the centre well. One-tenth millilitre of the oviduct fluid to be tested or $0.1 \mathrm{ml} \mathrm{KRP} \mathrm{for} \mathrm{control} \mathrm{was} \mathrm{added} \mathrm{to} \mathrm{the} \mathrm{side-arm.} \mathrm{Oxygen} \mathrm{consumption}$ measurements were made half-hourly and at the end of 1 or $1 \frac{1}{2} \mathrm{hr}$, the flasks were tipped to allow oviduct fluid or KRP to mix with spermatozoa. After mixing, oxygen consumption readings were taken every $\frac{1}{2} \mathrm{hr}$ for $2 \mathrm{hr}$. No attempt was made to control bacteria in the incubation flask. Respiration by bacteria, possibly a contaminant, did not influence oxygen uptake values; oxygen consumption of spermatozoa before mixing was the same whether KRP or oviduct fluid was in the side-arm.

The rate of oviduct secretion was greatest at oestrus $(0.77 \pm 0.46 \mathrm{ml} / 24 \mathrm{hr}$, mean \pm S.E.) and gradually dropped to $0.36 \pm 0.22 \mathrm{ml} / 24 \mathrm{hr}$ on the 4 th day after oestrus. During the rest of the cycle the rate remained relatively constant until just before the next oestrus.

Very few difficulties were encountered with the collection apparatus used in these studies. The use of a removable collection vial in place of the chamber encased in plastic greatly facilitated cleaning. In addition, use of the plastic case and vial decreased the weight of the apparatus. At autopsy there was 
little evidence of adhesions of the oviduct and no adverse effect of cannulation on oviduct epithelium was found below the point where the cannula entered the oviduct. As reported by Restall (1966), the epithelium in contact with the cannula was flattened. Below the cannula, the oviduct epithelium was similar to that of the contralateral oviduct.

Oviduct fluid does not contain much cellular material and, during the oestrous cycle, changes in the proportion of cellular components were not detected. Epithelial cells without visible nuclei were found in all samples of oviduct fluid examined. The next most commonly observed were isolated nuclei (observed in twenty of ninety-nine samples). The presence or absence of any cellular material could not be related to the stage of the oestrous cycle.

Oxygen uptake by spermatozoa was greatly increased when oviduct fluid was added to the incubation medium. The average oxygen uptake (176 samples) increased from $25 \cdot 8 \pm 1 \cdot 5 \mu \mathrm{O} \mathrm{O}_{2} / 30 \mathrm{~min}$ (KRP controls) to $45 \cdot 3 \pm 3 \cdot 3 \mu \mathrm{l}$ $\mathrm{O}_{2} / 30 \mathrm{~min}$ for spermatozoa with oviduct fluid $(P<0 \cdot 01)$. Stimulation was

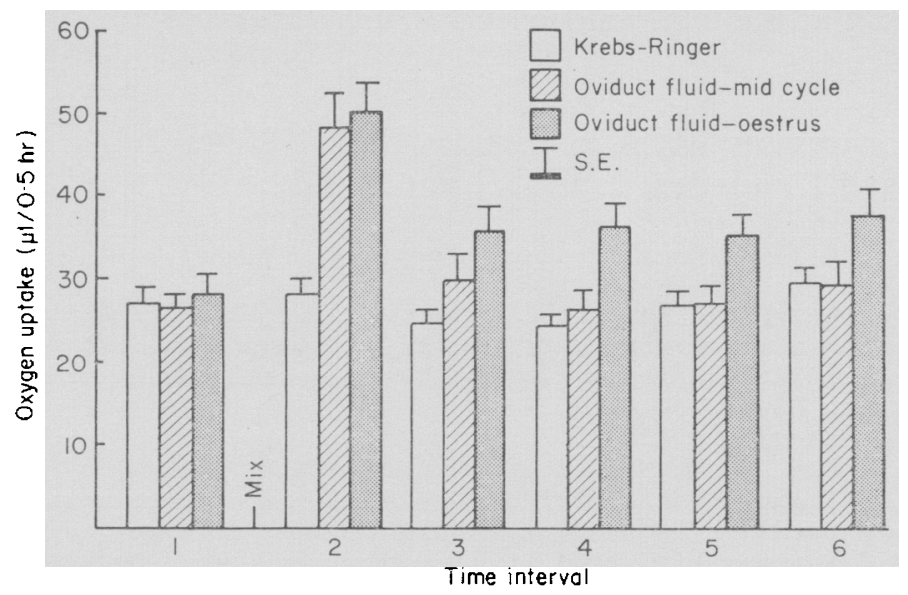

Text-Fig. 1. Oxygen uptake by ram spermatozoa in Krebs-Ringer solution alone and with oviduct fluid collected at oestrus and mid-cycle. Each Warburg flask contained $1 \mathrm{ml}$ sperm suspension. Both the control (KRP in side-arm) and treatment (oviduct fluid in side-arm) were mixed after $1 \frac{1}{2} \mathrm{hr}$.

transient and after the first $\frac{1}{2} \mathrm{hr}$, there was no significant difference between control and treated groups. There was, however, a tendency for the spermatozoa in oviduct fluid to consume oxygen more rapidly even after the first $\frac{1}{2} \mathrm{hr}$.

Oviduct fluid collected at oestrus stimulated oxygen uptake of spermatozoa, but fluid collected in mid-cycle ( 5 to 10 days after oestrus) did not stimulate oxygen uptake of spermatozoa (Text-fig. 1). For the 1st hr after mixing, there was no difference between the two: after the 1st hr, oxygen consumption by spermatozoa in oviduct fluid secreted at oestrus was significantly greater $(P<0.05)$ than for spermatozoa in oviduct fluid collected at mid-cycle.

The rate of oviduct secretion found in this experiment is lower than that presented earlier (Black et al., 1963) and that presented by Restall (1966). The difference may have been due, in part, to a few animals in which the secretion rate of oviduct fluid was low. It is assumed that the low secretory rate observed in these animals was normal. In these animals there was cyclic 
variation in the rate of secretion and post-mortem examination did not reveal oviduct distension which would have been expected if the cannulae had been occluded.

The difference in stimulation of oxygen uptake by spermatozoa suggests a change in the composition of oviduct fluid during the oestrous cycle. Restall \& Wales (1966) and Wales \& Restall (1966) found that oviduct fluid did not stimulate uptake of ram spermatozoa above control values (in $0.9 \% \mathrm{w} / \mathrm{v}$ sodium chloride) when glucose was present. They suggested that substrate alone is responsible for the observed stimulatory effect of oviduct fluid. Hamner \& Williams $(1963,1964)$ believe that bicarbonate ions in rabbit oviduct fluid are stimulatory to rabbit spermatozoa.

Whether the stimulatory property of oviduct fluid is due to substrate, bicarbonate ions or other materials, it is clear that an equal volume of oviduct fluid secreted at oestrus is more stimulatory to spermatozoa than fluid produced at mid-cycle. In addition, the oviduct produced at least twice as much fluid at oestrus so that the total amount available to spermatozoa in the oviduct is much greater.

This work was supported in part by United States Public Health Grant HD 00745 and Population Council Grant M-6432.

\section{REFERENCES}

Black, D. L., Crowley, L. V., Duby, R. T. \& Spilman, C. H. (1966) The effect of oviduct fluid on $\mathrm{O}_{2}$ uptake by ram spermatozoa. Fedn Proc. Fedn Am. Socs exp. Biol. 2, 190.

Black, D. L., Duby, R. T. \& Rersen, J. (1963) Apparatus for the continuous collection of sheep oviduct fluid. F. Reprod. Fert. 6, 257.

Clewe, T. H. \& MASTRoIANni, L. (1960) A method for continuous volumetric collection of oviduct secretions. F. Reprod. Fert. 1, 146.

Hamner, C. E. \& Williams, W. L. (1963) Effect of the female reproductive tract on sperm metabolism in the rabbit and fowl. 7. Reprod. Fert. 5, 143.

Hamner, C. E. \& Williams, W. L. (1964) Identification of sperm stimulating factor of rabbit oviduct fluid. Proc. Soc. exp. Biol. Med. 117, 240.

Olds, D. \& VanDemark, N. L. (1957) The behaviour of spermatozoa in the luminal fluids of bovine female genitalia. Am. 7. vet. Res. 18, 603.

Perkins, J. L., Goode, L., Wilder, W. A., Jr. \& Henson, D. B. (1965) Collection of secretions from the oviducts and uterus of the ewe. F. Anim. Sci. 24, 383.

Restall, R. J. (1966) The fallopian tube of the sheep. II. The influence of progesterone and oestrogen on the secretory activities of the fallopian tube. Aust. F. biol. Sci. 19, 187.

Restall, R. J. \& Wales, R. G. (1966) The fallopian tube of the sheep. IV. The metabolism of ram spermatozoa in the presence of fluid from the fallopian tube. Aust. F. biol. Sci. $19,883$.

Wales, R. G. \& Restall, R. J. (1966) The metabolism of ram spermatozoa in the presence of genital fluids of the ewe. Aust. F. biol. Sci. 19, 199. 